\title{
Effects of air pressure on flank wear in MQL cutting
}

\author{
Yasuhiro KAMATA $^{1}$ and Toshiyuki OBIKAWA ${ }^{2}$ \\ ${ }^{1}$ Institute of Industrial Science, The University of Tokyo, Japan, kamata@iis.u-tokyo.ac.jp \\ ${ }^{2}$ Institute of Industrial Science, The University of Tokyo, Japan, obikawa@iis.u-tokyo.ac.jp
}

\begin{abstract}
:
In this study, effect of air blowing pressure on flank wear was studied in MQL cutting. Using the general-purpose CFD software, the amount of oil-mist reached near the cutting point. From the result, the appropriate air blowing pressure range was existed in MQL finish-turning. On the other hand, high blowing pressure was more effective for the wear reduction of flank wear in MQL grooving. The tendencies of pressure gradient near the cutting edge were differed between the two cutting method. This difference was important for the understanding the mechanism of the wear suppression.
\end{abstract}

Keywords: MQL cutting, finish-turning, grooving, tool wear, air pressure, CFD

\section{Introduction}

For the high efficiency MQL (Minimal Quantity Lubrication) cutting, it is important to search the effective supply conditions of oil-mist [1]. For example, the position of nozzle exit, blowing pressure of oil-mist, diameter of oil, the component of cutting fluids, and so on. The authors focused attention on the air blowing pressure. We conducted the cutting experiment for MQL grooving, and revealed that the increase of air blowing pressure was enlarged the tool lives [2]. We also conducted the cutting area the cutting experiment for MQL finish-turning or the case to change the value of the blowing pressure of compressed air [3]. From the result, it turned out that there is a suitable air blowing pressure domain for the effective suppression of corner wear in MQL finish-turning. Therefore, in MQL cutting, the wear suppression effect changes according to the blowing pressure of compressed air. To understand this phenomenon, knowing a lubrication mechanism in the cutting zone becomes important. And, it is important to know the flow field of the oil mist near the cutting edge.

In this study, the fluid analysis was executed for the MQL grooving and MQL finish-turning for the case to change the value of the blowing pressure of compressed air. It is compared the analytical result with the experiment result for the wear suppression effect. And, the difference of wear suppression mechanism between MQL finish-turning (cutting area between tool flank and workpiece was open space) and MQL grooving (cutting area between tool flank and workpiece was closed space) was discussed.

\section{MQL grooving}

2.1 Experimental result

MQL grooving of a bar of $0.45 \% \mathrm{C}$ carbon steel was conducted. Many grooves $5.1 \mathrm{~mm}$ wide and $7.5 \mathrm{~mm}$ deep were machined. A P35 TiC/TiCN/TiN coated carbide tip was used in this study. Cutting speed was $4.0 \mathrm{~m} / \mathrm{s}$. Feed rate was $0.12 \mathrm{~mm} / \mathrm{rev}$. For the MQL cutting, nozzle exit on a flank of the tool shank which diameter was $2.0 \mathrm{~mm}$ was $8.3 \mathrm{~mm}$ away from the cutting edge along the surface finish. Air blowing pressure $P$ was set at $0.3,0.5$ and 0.7MPa. Aside from the normal shank with oil-hole, the tool shown in Fig. 1 was used for the control of oil-mist as the oil-mist was blown to the center of cutting edge intensively. This tool is called COD (controlled oil-mist direction) tool.

Experimental result was shown in Fig. 2. Increase of air pressure was raised up the wear suppression effect. And the control of oil-mist using the COD tool was produced the increase of wear suppression effect.

\subsection{Analytical result}

Using the general purpose heat fluid analysis code PHOENICS, analysis of oil mist flow of MQL grooving was conducted by finite volume method. In this analytical case, Reynolds number of compressed air via a shank is bigger enough than critical Reynolds number (about 2300). So, turbulent flow is considered in this analysis. Standard k-e model was selected as a turbulent model. In MQL cutting, oil consumption rate is much smaller than compressed air consumption rate. So, It was supposed that oil mist was included in compressed air uniformly,

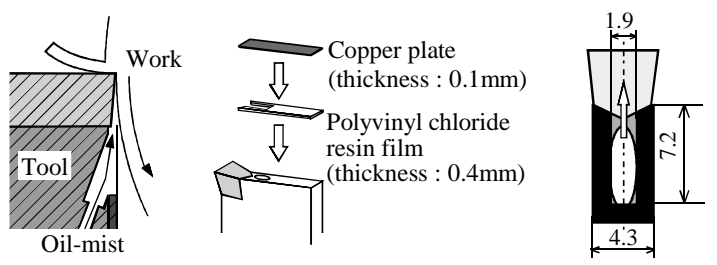

Figure 1: COD(Controlled Oil-mist Direction) tool 


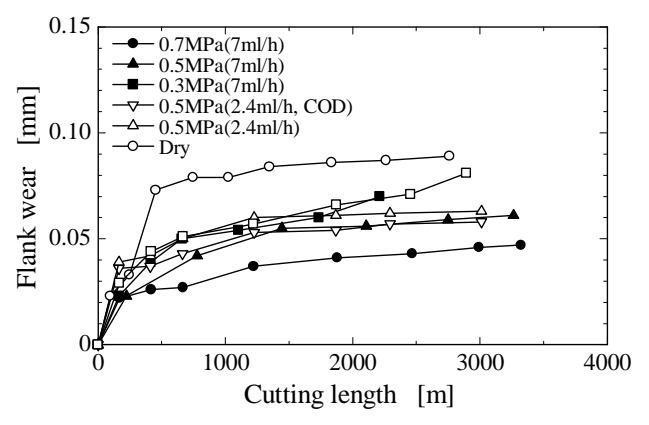

Figure 2: Effect of air pressure of MQL on tool wear in grooving. Cutting conditions: cutting speed, 4.0 $\mathrm{m} / \mathrm{s}$; feed rate, $0.12 \mathrm{~mm} / \mathrm{rev}$.

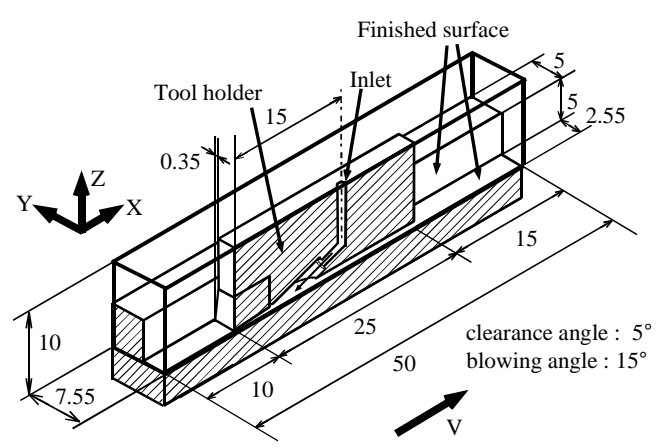

Figure 3: Analytical model in MQL grooving

and it was analyzed the flow of only compressed air.

Analytical model is shown in Fig. 3. X direction (cutting direction) was $50 \mathrm{~mm}$. Y direction (the direction of tool width) was $15.1 \mathrm{~mm}$. $\mathrm{Z}$ direction (perpendicular direction to the surface finish) was $10 \mathrm{~mm}$. About the modeling of analytical field, it was assumed that surface finish was flatness. The number of structured grid in this analysis was 388960. As boundary condition, blowing pressure and inflow speed was set in the inlet. From the cutting experiment, the value of inflow speed was set 140 $\mathrm{m} / \mathrm{s}$ using normal shank in any blowing pressure conditions and $123 \mathrm{~m} / \mathrm{s}$ using the COD tool. Cutting speed was set in the surface finish. Atmospheric pressure was set in the open boundary.

In this analysis, the flow rate reached near the cutting edge was analyzed for comparison with the experimental result. Evaluation cross-sectional area was set at the $0.1 \mathrm{~mm}$ away along the surface finish from the cutting edge. Evaluation cross-sectional area was XY cross-section. The width of evaluation cross-sectional area was $3 \mathrm{~mm}$ and set the center of groove. It was analyzed the mass flow rate into the evaluation area. And it was calculated the ratio the mass flow rate reached at the evaluation area to that from the nozzle exit. This ratio becomes equivalent to the delivered rate into the cutting area of cutting oil to the amounts of all oil consumption.

The flow field was shown in Fig. 3. The mist flow changed its flow direction parallel to the cutting edge. And the oil-mist was flown out of the analytical area in nearly parallel with the side cutting edge. This flow pattern changed little with blowing pressure. The pressure gradient at the center of tool width and $0.075 \mathrm{~mm}$ above the finished surface is shown in Fig. 4. In MQL grooving,

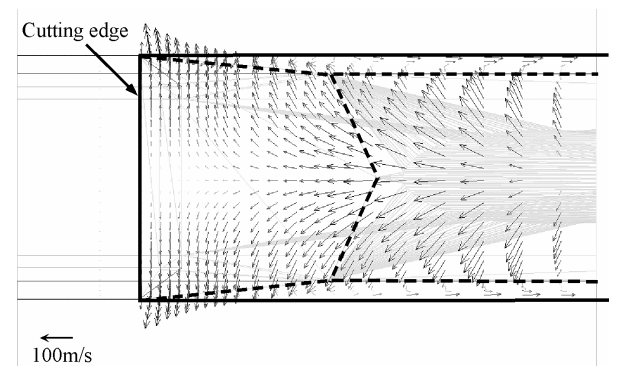

Figure 4: Air flow vector on a plane $0.075 \mathrm{~mm}$ above the finished surface (no cover)

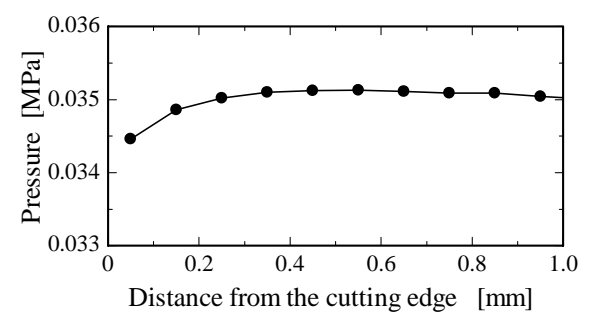

Figure 5: Pressure gradient $(P=0.3 \mathrm{MPa})$

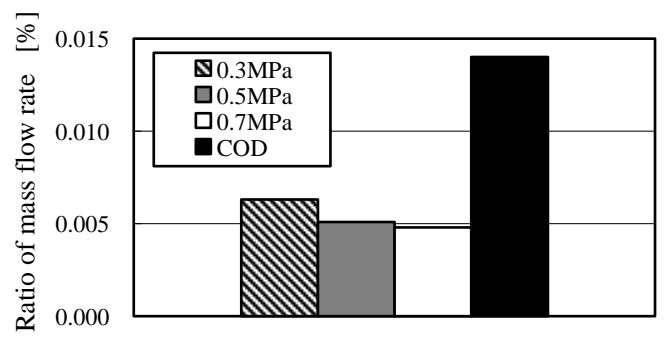

Figure 6: Effect of the blowing pressure on the mass flow rate

Table 1: Variables and partial regression coefficients B of regression analyses. $X p$ is the explaining variable of air pressure. $X a$ is that of ratio of mass flow rate. $X o$ is that of oil supply rate.

\begin{tabular}{l|r|r|r|r}
\hline & \multicolumn{1}{|c|}{$Y$} & \multicolumn{1}{c|}{$X p$} & \multicolumn{1}{c}{$X a$} & \multicolumn{1}{c}{$X o$} \\
\hline $0.7 \mathrm{MPa}(7 \mathrm{ml} / \mathrm{h})$ & 1.528 & 1.414 & -0.576 & 0.730 \\
\hline $0.5 \mathrm{MPa}(7 \mathrm{ml} / \mathrm{h})$ & 0.059 & 0.000 & -0.500 & 0.730 \\
\hline $0.3 \mathrm{MPa}(7 \mathrm{ml} / \mathrm{h})$ & -1.214 & -1.414 & -0.194 & 0.730 \\
\hline $0.5 \mathrm{MPa}(2.4 \mathrm{ml} / \mathrm{h}$, cover $)$ & 0.059 & 0.000 & 1.769 & -1.095 \\
\hline $0.5 \mathrm{MPa}(2.4 \mathrm{ml} / \mathrm{h})$ & -0.431 & 0.000 & -0.500 & -1.095 \\
\hline$B$ & & 0.999 & 0.218 & 0.296 \\
\hline
\end{tabular}

the pressure drop was generated. The result of the ratio of mass flow rate was shown in Fig. 5. The ratio was decreased by increase of $P$. Using COD tool, the ratio is drastically increase. The regression analysis was conducted to evaluate the effective parameter of MQL for the flank wear. The result was shown in Table 1. From the result, air blowing pressure was most effective parameter for the suppression of flank wear.

\section{MQL finish-turning}

\subsection{Experimental}

MQL finish-turning of nickel based superalloy, Inconel 718 was carried out. Cutting speed was set at $1.0 \mathrm{~m} / \mathrm{s}$. Feed rate was $0.1 \mathrm{~mm} / \mathrm{rev}$. Depth of cut was 

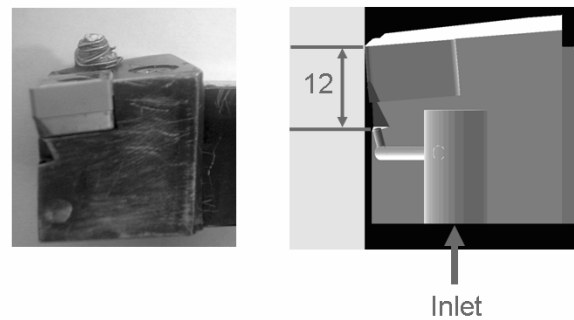

Figure 7: Tool shank with oil-hole

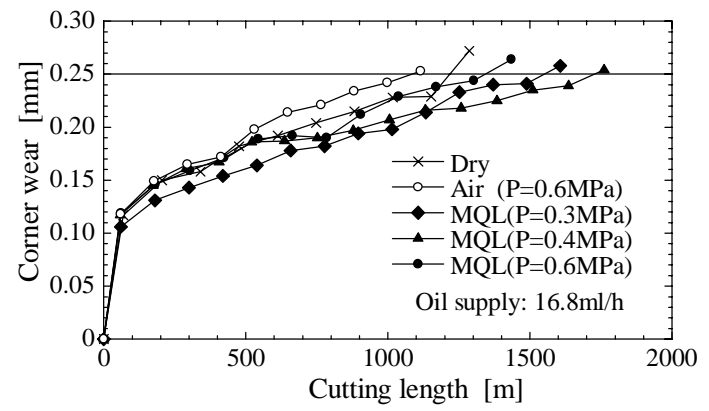

Figure 8: Influence of MQL finish turning of Inconel 718 Cutting conditions: cutting speed, $1.0 \mathrm{~m} / \mathrm{s}$; feed rate, $0.1 \mathrm{~mm} / \mathrm{rev}$; depth of cut, $0.1 \mathrm{~mm}$.

$0.1 \mathrm{~mm}$. A cutting tool used is CVD TiCN/ $\mathrm{Al}_{2} \mathrm{O}_{3} / \mathrm{TiN}$ coated carbide insert (CNMG120408), which surface layer was TiN. Oil consumption is set at $16.8 \mathrm{ml} / \mathrm{h}$. Nozzle exit on a flank of the tool shank which diameter was 1 $\mathrm{mm}$ was $12 \mathrm{~mm}$ away from the cutting edge along the surface finish. This nozzle exit is shown in Fig. 7. Tool life is the time when the size of corner wear reached at $0.25 \mathrm{~mm}$. In the cutting experiment, air blowing pressure $P$ is set at three conditions of $0.3,0.4$ and $0.6 \mathrm{MPa}$.

Experimental result is shown in Fig. 8. From the result, the case of a tool life of $P=0.4 \mathrm{MPa}$ was the longest tool life. In the case of air blow cutting (cutting oil was not use and $P=0.6 \mathrm{MPa}$ ), tool life is shorter than dry cutting. It is thought that the oxidation of a TiN coating film was promoted by atmospheric oxygen sent into the cutting zone. When TiN exceeds about 550 degrees Celsius, the oxidation is started. And $\mathrm{TiN}$ changes in $\mathrm{TiO}_{2}$. Original characteristic of a coating film is lost by this and tool wear is promoted. And in MQL finish-turning, it turned out that there is a suitable air blowing pressure domain.

\subsection{Analytical result}

Same as the case of MQL grooving, analysis of oil mist flow of MQL finish-turning was conducted using CFD software, PHOENICS. Analytical model is shown in Fig. 9. $\mathrm{X}$ axis is the direction of depth of cut. $\mathrm{Y}$ axis is the feed direction. $\mathrm{Z}$ axis is cutting direction. The size of analytical region is $300 \mathrm{~mm}(\mathrm{X}$ direction) $\times 230 \mathrm{~mm}(\mathrm{Y}$ direction $) \times 125 \mathrm{~mm}(\mathrm{Z}$ direction $)$. About the modeling of analytical region, it was assumed that surface finish was flatness. The number of structured grid in this analysis was 598400. As boundary condition, blowing pressure and inflow speed was set in the inlet. From the cutting experiment, the value of inflow speed was about $2.7 \mathrm{~m} / \mathrm{s}$ in any blowing pressure conditions. Cutting speed was set in the surface finish. Atmospheric pressure was set in the open boundary. In this analysis, the flow rate reached

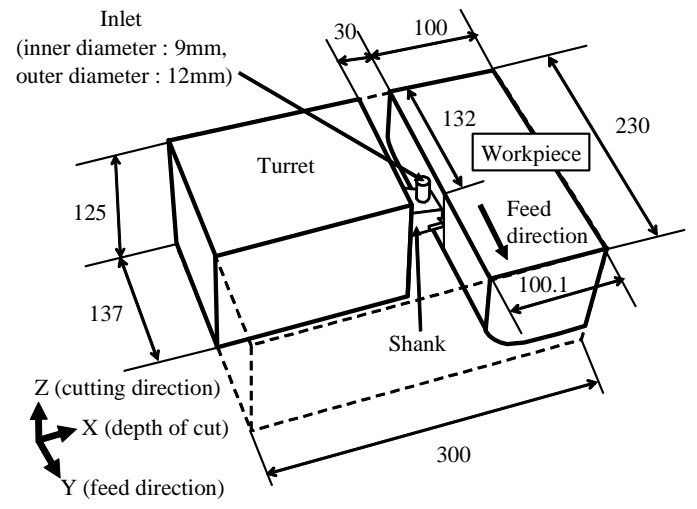

Figure 9: Analytical model in MQL finish-turning

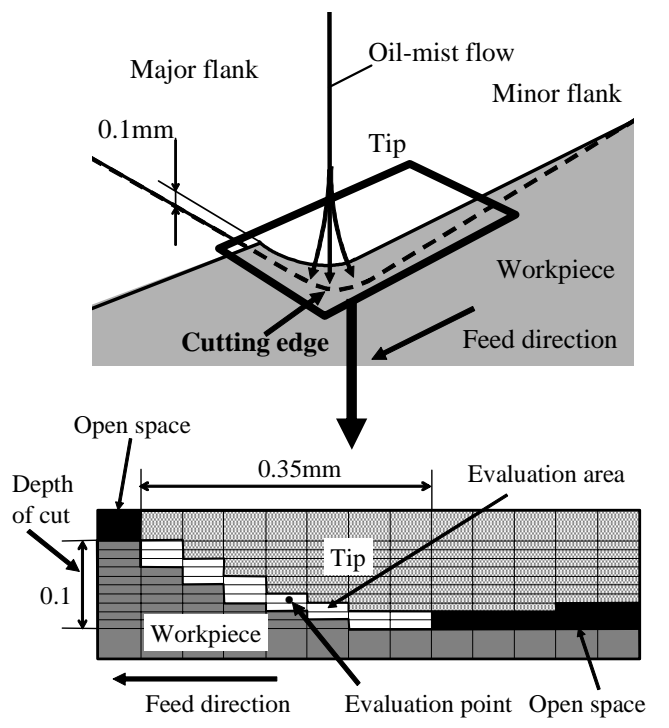

Figure 10: Mesh on a XY plane $0.1 \mathrm{~mm}$ above the cutting edge

near the cutting edge was analyzed for comparison with the experimental result. It thinks about the distance of the direction of $\mathrm{z}$ negative axis for the starting point by thinking about cutting edge in the model of Fig. 8. It thinks about XY plane by the distance at $0.1 \mathrm{~mm}$ intervals, and the mass flow of the air that flows into the space (evaluation area showed in Fig. 10) between the flank face and surface finish was analyzed.

The oil-mist flow field in the tool flank is shown in Fig. 11. For the result, workpiece does not display it. More of the oil-mist flow blowing from the nozzle exit was headed to the major flank side. It is considered that the open space between the tool flank and the surface finish in the minor flank side was narrow. Near the cutting edge, oil-mist flow was headed from the minor flank side to the major flank side. Figure 12 shows the pressure gradient at the evaluation point shown in Fig.10. The more it approached the cutting edge, the more air pressure rose. The pressure value in the cutting area increases when the air blowing pressure $P$ is raised. In the case that air blowing pressure was changed, the ratio of mass flow rate at position $0.1 \mathrm{~mm}$ away from the cutting edge is shown in Fig. 13. As a result, the ratio of mass flow rate at $0.4 \mathrm{MPa}$ of air blowing pressure was the 


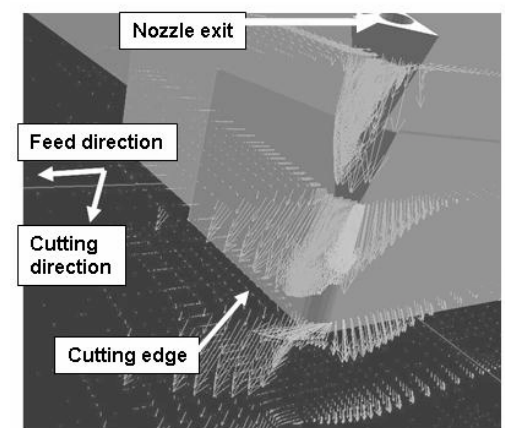

Figure 11: Oil-mist flow field in the tool flank

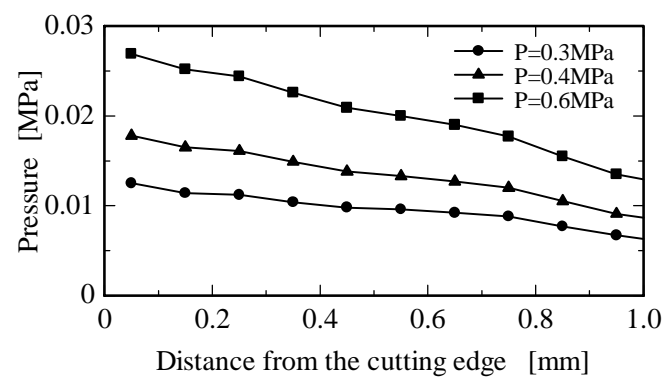

Figure 12: Pressure gradient in MQL finish-turning

largest value. From this result, it turned out that there is a suitable air blowing pressure domain to optimize the supply of oil-mist to the cutting zone. As shown in section 3.1, suitable range of air blowing value was existed in MQL finish-turning.

Figure 14 shows the analytical results of pressure gradient near the cutting edge for MQL turning and MQL grooving. In this figure, the case that pressure drop was occurred was positive value. In the case of MQL grooving, the suction was occurred near the cutting edge. Oil mist was suctioned to the cutting zone by pressure drop. Pressure drop was increased by increase of $P$. So, more amount of oil-mist was suctioned by increase of $P$, and wear suppression effect was raised. On the other hand, the suction was not occurred in MQL finish-turning. Therefore, oil-mist was hard to proceed into the cutting zone. So, the amounts of oil mist reached to the cutting edge were important in MQL finish-turning.

\section{Conclusions}

In this research, fluid analysis was executed for the MQL grooving and MQL finish-turning. It compared from the flow field near the cutting edge with the experimental result. And the difference of wear suppression effect on the blowing pressure of compressed air between MQL finish-turning and MQL grooving was discussed.

As a result, In MQL finish-turning, appropriate blowing pressure range to supply the oil-mist into the cutting point efficiently was existed. On the other hand, tool wear was suppressed by the increase of air blowing pressure in MQL grooving. The big difference between MQL grooving and MQL finish-turning was presence or absence of the suction near the cutting edge. In MQL grooving, the pressure drop was existed. And it increased

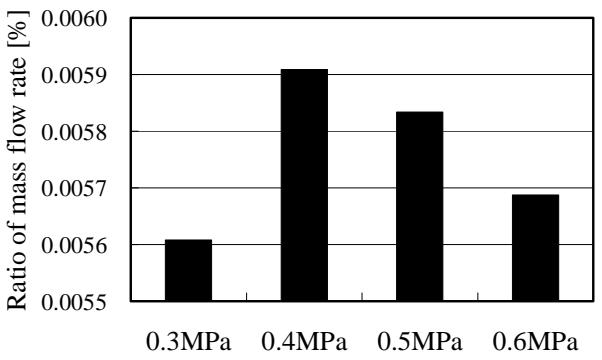

Figure 13: Effect of the blowing pressure on the mass flow rate in MQL finish-turning

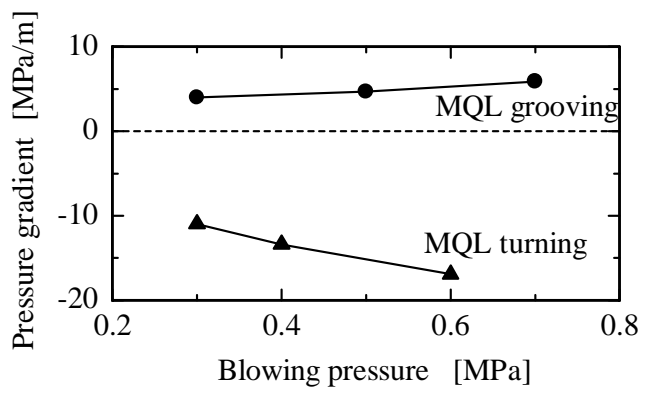

Figure 14: Difference of pressure gradient near the cutting edge

by the increase of blowing pressure. Therefore, tool wear was suppressed by the increase of air blowing pressure. In MQL finish-turning, pressure drop was not existed. So, wear suppression effect was closely relation to the oil-mist rate arrived at the cutting area in MQL finish-turning. Consequently, it was shown the importance to understand the action of the oil-mist flow near the cutting edge.

\section{Acknowledgements}

The authors acknowledge Nagoya Guidance and Propulsion systems Works of Mitsubishi Heavy Industries Ltd. for support to a part of the research. They also acknowledge Nippon Oil Corporation for supplying the lubricant. This paper is partly based on research supported by Grant-in-Aids for Scientific Research ((B)(2), 14350068, 2002 and (B)(2) 17360060, 2005), Japan. This paper is also partly based on research supported by Grant-in-Aid for Young Scientists ((B) 18760094, 2006), Japan.

\section{References}

[1] de Lacalle, L. N. L., Angulo, C., Lamikiz, A., Sanchez, J.A., 2006, Experimental and numerical investigation of the effect of spray cutting fluids in high speed milling, J. Mater. Process. Technol., Vol.172, pp.11-15.

[2] Obikawa, T., Kamata, Y., Shinozuka, J., 2006, High-speed grooving with applying MQL, Int. J. Mach. Tools Manuf., Vol.46, pp.1854-1861.

[3] Kamata, Y., Obikawa, T., 2007, High speed MQL finish-turning of Inconel 718 with different coated tools, J. Mater. Process. Technol., Vol.192-193, pp.281-286. 